\title{
A Lectin Disrupts Vector Transmission of a Grapevine Ampelovirus
}

\author{
Cecilia A. Prator@ and Rodrigo P. P. Almeida *(1) \\ Department of Environmental Science, Policy and Management, University of California, Berkeley, CA 94720, \\ USA; cprator@berkeley.edu \\ * Correspondence: rodrigoalmeida@berkeley.edu
}

Received: 6 July 2020; Accepted: 31 July 2020; Published: 1 August 2020

\begin{abstract}
Grapevine leafroll disease is one of the most important virus diseases of grapevines and occurs in every major grape-growing region of the world. The vector-transmission mechanisms of the causative agent, Grapevine leafroll-associated virus 3 (GLRaV-3), remain poorly understood. We show that the vine mealybug, Planococcus ficus, feeds through a membrane feeding system on GLRaV-3 viral purifications from both $V$. vinifera and $N$. benthamiana and transmits the virus to test plants from plants from both species. Building on this strategy, we used an immunofluorescence approach to localize virions to two retention sites in P. ficus mouthparts. Assays testing molecules capable of blocking virus transmission demonstrated that GLRaV-3-transmission by P. ficus could be disrupted. Our results indicate that our membrane feeding system and transmission-blocking assays are a valid approach and can be used to screen other candidate blocking molecules.
\end{abstract}

Keywords: Grapevine leafroll-associated virus 3; Grapevine leafroll disease; Closteroviridae; Ampelovirus; Planococcus ficus; vine mealybug

\section{Introduction}

Insect vectors play an essential role in the dissemination of many viruses that cause diseases in humans, animals, and plants. Vector-transmission is a complex event in the virus disease cycle and can be divided into virus acquisition, retention, and inoculation processes. Most plant viruses rely on vectors for efficient transmission, such as fungi, nematodes, and arthropods [1]. Insects are the most common vectors of plant pathogens, and specific relationships, as well as specific transmission mechanisms, exist between a given virus genus and vector species. However, the molecular determinants of virus-vector interactions of many important viruses remain poorly understood.

Plant virus-insect vector relationships are characterized by properties associated with virus acquisition, retention, and transmission. There are four basic types of virus-vector relationships: nonpersistent and semipersistent, both of which are noncirculative, as well as circulative nonpropagative and propagative, where the virus enters via the gut and circulates or replicates within the insect body, respectively [2]. Specific viral proteins, molecular domains, and sequence motifs required for virus binding to vectors have been identified for the major viral genera transmitted by insect vectors [2]. Viral coat proteins and other accessory proteins (helper components) mediate interactions required for virus transmission [1]. The identity of putative virus receptors in vectors remains elusive. However, a recent study identified a protein-rich region (called "the acrostyle") at the tip of aphid stylets, which functions as the binding site for Cauliflower mosaic virus (CaMV) [3]. This research was the first to identify proteins as putative vector receptors for a noncirculative plant virus as well as provided definitive proof of a noncirculative virus retention site located at the stylet tips of hemipteran insects [4]. Further advances in this system have allowed the identification of Stylin-1, the first cuticular protein specifically described in aphid stylets [5]. For other vector-borne plant viruses transmitted 
non-persistently, virus-encoded proteins specifically interact with receptors in the vector, allowing for retention and, consequently, successful transmission between plants [1]. In contrast to CaMV, the viral retention site for a semipersistent virus, Lettuce infectious yellows virus (LIYV), has been localized to the cibarium of whitefly vectors instead of stylet tips [6]. Citrus tristeza virus (CTV), another related semipersistent virus, has also been shown to be localized to the cibarium of an aphid vector [7].

Grapevine leafroll-associated virus 3 (GLRaV-3) is associated with grapevine leafroll disease (GLD), an important problem in California and all grape-growing regions of the world [8]. GLRaV-3 is an $18 \mathrm{~Kb}$ ssRNA Ampelovirus in the family Closteroviridae transmitted by phloem-sap-sucking mealybugs (Hemiptera, Pseudococcidae) and soft scales (Coccidae). GLRaV-3 is transmitted in a semipersistent manner; insect vectors can retain the virus for a period of a few days [9]. The specific retention site and transmission mechanisms for any Ampelovirus have not yet been described.

The vine mealybug (Planococcus ficus) is an invasive pest in most grape-growing regions worldwide, as well as an efficient vector of GLRaV-3 [10]. Mealybug nymphs and adult females have specialized piercing-sucking mouthparts that play an important role in virus transmission. Adult males have modified non-functional mouthparts and therefore are unable to spread the virus. The stylet bundle is composed of two maxillary stylets and two mandibular stylets contained in the labium [11]. When the mealybug does not feed, the stylet bundle is retracted as a loop in the body cavity of the insect inside a sheath called the crumena [12]. There is no evidence that the maxillary stylet tips in mealybugs contain the acrostyle region found to be associated with virus retention and transmission in aphids [13]. The food canal is connected to the foregut, comprising the precibarium, the cibarium, equipped with a muscular pump, and the esophagus [11]. During feeding, mealybugs extend the stylets into plant vascular tissues where the ingestion of primarily phloem begins, although xylem-sap feeding has also been documented through electropenetrography [14]. GLRaV-3 is phloem-restricted in both Vitis vinifera and Nicotiana benthamiana; thus, mealybug vectors must ingest phloem-sap to acquire virions for subsequent transmission [15].

The mechanisms of virus-vector interactions of GLRaV-3 in mealybugs are poorly understood. In this work, we used a membrane feeding system to show that GLRaV-3 can be transmitted from purified preparations of $V$. vinifera or $N$. benthamiana. Using an immunofluorescence approach, virions were localized to two retention sites in P. ficus mouthparts. We also tested molecules capable of disrupting virus transmission to gain a general idea of virus-vector interactions. We were successfully able to block GLRaV-3-transmission in P. ficus, demonstrating this approach is valid and can be used to screen other candidate blocking molecules.

\section{Materials and Methods}

\subsection{Membrane Feeding Transmission Assays}

P. ficus colonies were maintained on butternut squash (Cucurbita moschata) at $22{ }^{\circ} \mathrm{C}$, with a 16:8-h photoperiod. First instars were used for all experiments because they were shown to be the most efficient vector of GLRaV-3 [9]. GLRaV-3 virions (accession LR101; variant I) were purified as previously described $[15,16]$. Whole virion integrity from purifications was confirmed previously [15]. Three resuspended virion purification aliquots from either $N$. benthamiana expressing the turnip mosaic virus P1/HC-Pro or V. vinifera were immediately pooled and added to $1.8 \mathrm{~mL}$ of an artificial diet composed of $15 \%$ sucrose and $1 \%$ BSA in TE, as described previously [6]. Transgenic tobacco expressing P1/HC-Pro, an antiviral silencing suppressor, were used because transmission efficiencies using wildtype tobacco were very low, and previously published studies showed increased numbers of P1/HC-Pro N. benthamiana plants became infected when compared to wildtype N. benthamiana [15]. An artificial diet without the addition of purified virions was used as a control. Diets were placed in small glass dishes. Approximately 20 mealybugs were placed in 14- by 20-mm (diameter by height) plexiglass feeding chambers, and the opening was covered by a layer of thinly stretched parafilm. The feeding chamber was then placed, parafilm side down, into a small dish containing either artificial 
diet with GLRaV-3 virions or just artificial diet and covered to prevent light disruption. Mealybugs were given an acquisition access period (AAP) of $24 \mathrm{~h}$ on each respective diet before being manually removed from the feeding chamber with a small paintbrush and moved to healthy test $N$. benthamiana or $V$. vinifera (cv. Cabernet Sauvignon) ( $n=10$ mealybugs per plant). After a 4-day inoculation access period (IAP), mealybugs were manually removed from the test plant, and plants were treated with pesticides and moved to the greenhouse. Petiole samples were collected from all plants 4 months post-inoculation, and RNA extractions were completed on $100 \mathrm{mg}$ of petiole tissue [17]. One-step reverse transcription-polymerase chain reaction (RT-PCR) was then performed, and PCR products were analyzed using fragment analysis as described previously [17]. The primers used were Fwd 5'NED-AAG TGC TCT AGT TAA GGT CAG GAG TGA-3' and Rev 5' - GTA TTG GAC TAC CTT TCG GGA AAA T-3'. Logistic regression analysis was performed using R (Version 3.0.2, R. RStudio, Inc., Boston, MA, USA [http://www.rstudio.com/]).

\subsection{Virion Localization Assays}

Potential virion retention sites in mealybug vectors were localized following the protocol previously described [6]. For artificial diet experiments, approximately 100 first instar mealybugs at a time were placed in feeding chambers as described above and placed on artificial diets with or without GLRaV-3 virions for a 12-h AAP. This assay was repeated for 14 biologic replicates. In a second experiment, mealybugs were placed on GLRaV-3 source or healthy vine cuttings (accession LR101; variant I) for a 12-h AAP ( 3 biologic replicates). A 12-h AAP was used in localization assays after we determined that AAPs longer than $12 \mathrm{~h}$ resulted in lower labeling efficiencies (CAP personal observations). Mealybugs were then placed on a second diet containing a 1/800 dilution of rabbit anti-GLRV-3 polyclonal antisera (kindly supplied by Dr. Adib Rowhani, UC Davis) for $12 \mathrm{~h}$ followed by a third artificial diet containing a 1/200 dilution of goat anti-rabbit antisera conjugated with Alexa Fluor 488 (Invitrogen, Carlsbad, USA) for 12 more hours. A final artificial diet was presented to the mealybugs for $4 \mathrm{~h}$ as a wash to remove any nonspecifically bound virions or leftover antibodies present in the mouthparts. Mealybugs were placed on a glass slide in a drop of glycerol, covered with a coverslip and observed using a Zeiss Axio Imager fluorescence microscope using a YFP filter set (Chroma Filter Set $\# 49,003$ ) to minimize mealybug autofluorescence (excitation 490-510 nm, dichroic $515 \mathrm{~nm}$, emission filter 520-550 nm). Images were captured using a QIClick digital CCD grayscale camera. The biologic replicates were combined, and logistic regression analysis was performed using $\mathrm{R}$.

\subsection{Virus Transmission}

Five to ten mealybugs were placed in feeding chambers, and the opening was covered by a layer of thinly stretched parafilm as described above. The feeding chambers were then placed, parafilm side down, into a small dish containing either artificial diet with a competitor molecule or just artificial diet for a 12-h AAP. The competitor molecules chosen were the lectin wheat germ agglutinin $(0.1 \%$ $v / v)$ with expected affinity to substrates on the cuticle of insect vectors [18] and casein $(0.1 \% v / v)$, a molecule commonly used to block nonspecific binding of proteins. Mealybugs were then moved to an artificial diet containing viral purifications from grapevines as described above for another $12 \mathrm{~h}$, followed by manual placement onto test $V$. vinifera for a 4-day IAP. Petiole samples were collected from plants 4 months post-inoculation, and RNA extractions and RT-PCR were completed as described above. Logistic regression with Firth's bias correction was used because no acquisition or inoculation occurred in the sucrose treatment resulting in all zeroes (quasi-complete separation of factor levels) [19]. Analyses were performed using R and the logistf package for Firth's logistic regression [20]. 


\section{Results}

\subsection{Mealybug Transmission of GLRaV-3 through an Artificial Diet Membrane System}

To determine if $P$. ficus could transmit GLRaV-3 from artificial diets to test plants, experiments with virus purified from both $V$. vinifera and P1/HC-Pro $N$. benthamiana were conducted (Table 1). Our results indicate that $P$. ficus feeds on solutions from both purified GLRaV-3 plant sources through parafilm membranes and transmits the virus to $V$. vinifera and P1/HC-Pro N. benthamiana; P. ficus transmitted GLRaV-3 from $V$. vinifera virus purifications to 12 out of $94 \mathrm{~V}$. vinifera, and only 1 out of 187 P1/HC-Pro N. benthamiana tested four months post-inoculation; P. ficus specimens fed on diets containing P1/HC-Pro N. benthamiana virus-purifications transmitted GLRaV-3 to 1 out of $84 \mathrm{~V}$. vinifera and 2 out of 125 P1/HC-Pro N. benthamiana recipient plants. The main effects of source $(p=0.368$, $z=-0.900$ ) or recipient ( $p=0.808, z=-0.243$ ) plants did not have a significant effect on transmission rates. The interaction within the same plant species transmission was significant when compared to interactions between the two different species $(p=0.026, \mathrm{z}=2.226)$. All trials, including $P$. ficus feeding on artificial diet without purified virus as controls, resulted in no transmission.

Table 1. Planococcus ficus transmits GLRaV-3 from purified virus fed through a membrane system. GLRaV-3 was purified from both Vitis vinifera and P1/HC-Pro Nicotiana benthamiana source plants and successfully transmitted by insect vectors feeding on artificial diets with an acquisition access period of $24 \mathrm{~h}$ followed by a four-day inoculation access period on test plants. All trials included P. ficus feeding on artificial diet without purified virus as controls.

\begin{tabular}{cccc}
\hline Source & Recipient & Plants Infected/Plants Inoculated & Control \\
\hline V. vinifera diet & V. vinifera & $12 / 94$ & $0 / 18$ \\
& N. benthamiana & $1 / 187$ & $0 / 37$ \\
N. benthamiana diet & V. vinifera & $1 / 84$ & $0 / 17$ \\
& N. benthamiana & $2 / 125$ & $0 / 25$ \\
\hline
\end{tabular}

\subsection{GLRaV-3 Virions Are Retained in the Mouthparts of Vectors}

$P$. ficus were sequentially fed on separate artificial liquid diets containing first, purified GLRaV-3 virions, second, anti-GLRaV-3 IgG, and third, a diet with goat anti-rabbit IgG conjugated with Alexa Fluor 488. A final short wash step on artificial diet alone was included to reduce any nonspecific binding. The same experiment was repeated, placing P. ficus on GLRaV-3-infected grapevines instead of viral purifications during the first step, followed by subsequent diets as described above. All trials included $P$. ficus feeding on artificial diet without purified virus or on healthy plants as controls. No fluorescent labeling was observed in the control experiments. Our results show that GLRaV-3 was retained in two binding sites in insect mouthparts (Figure 1). When feeding on purified virions, 19 out of the 645 specimens of $P$. ficus showed a fluorescent signal in the tip of stylets retracted in the labium (Figure 1b, Figure S1). Fluorescent signal was observed in the cibarium of 11 individuals (Figure 1c); in one insect signal was observed in both the cibarium and stylet (Table 2). No labeling was observed in any of the 149 insects fed on artificial diet without virions. When $P$. ficus was provided with GLRaV-3-infected plants instead of purified virions, four insects were observed with a fluorescent signal in the tip of stylets, and four insects showed labeling in the cibarium out of 298 individuals observed. No labeling was observed in any of the 35 mealybugs fed on healthy plants. There was no significant effect of the diet (artificial or cuttings) ( $p=0.808, \mathrm{z}=-0.242$ ) on the location of the signal observed, and there was no significant difference in whether the signal was located in the stylet or cibarium $(p=0.190, \mathrm{z}=1.311)$ of insects observed. 

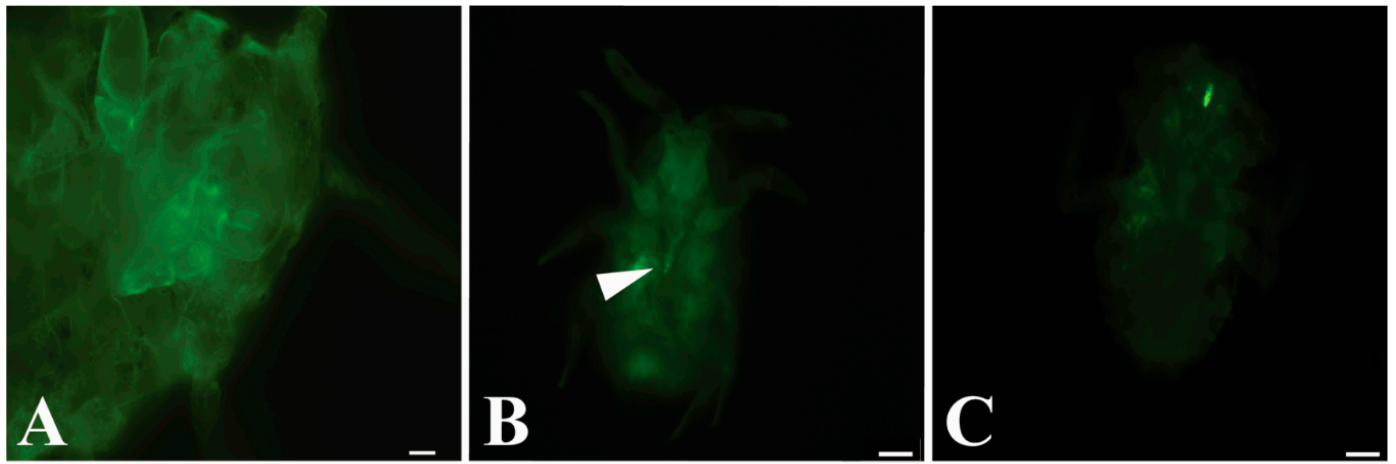

Figure 1. GLRaV-3 virions are retained in the mouthparts of $P$. ficus vectors. (A) First instar head of $P$. ficus control after feeding on membrane diet containing sucrose without virions followed by subsequent antibody labeled diets showing no labeling. Chitin in insects can be autofluorescent, accounting for the small signal observed. (B) Retention of GLRaV-3 virions in the retracted stylet tips (near white arrow) or (C) cibarium of $P$. ficus after sequential membrane feeding immunolocalization assay. Bars represent $20 \mu \mathrm{m}$.

Table 2. Summary of GLRaV-3 retention site observations. Planococcus ficus fed on either artificial diet augmented with GLRaV-3 virions or vine cuttings for $12 \mathrm{~h}$, followed by $12-\mathrm{h}$ acquisition access times on diets containing anti-GLRV-3 polyclonal antisera and antisera conjugated with Alexa Fluor 488 , respectively.

\begin{tabular}{|c|c|c|c|c|c|}
\hline \multicolumn{2}{|l|}{ Source } & \multirow{2}{*}{$\begin{array}{c}\text { Stylet } \\
19\end{array}$} & \multicolumn{2}{|c|}{ Cibarium Both } & \multirow{2}{*}{$\begin{array}{c}\text { Total } \\
31\end{array}$} \\
\hline Artificial diet & Number of $P$. ficus labeled & & 11 & 1 & \\
\hline & P. ficus controls ${ }^{*}$ & 0 & 0 & 0 & 149 \\
\hline & Total P. ficus viewed & & & & 794 \\
\hline \multirow[t]{3}{*}{ GLRaV-3 vine cuttings } & Number of $P$. ficus labeled & 4 & 4 & 0 & 8 \\
\hline & P. ficus controls ${ }^{\dagger}$ & 0 & 0 & 0 & 35 \\
\hline & Total P. ficus viewed & & & & 333 \\
\hline
\end{tabular}

\subsection{GLRaV-3-Transmission Is Blocked by a Lectin}

Because GLRaV-3 appears to be retained in one or two binding sites, further questions remain regarding the nature of the receptors involved in the mouthparts. Virus transmission experiments were conducted by providing a blocking compound to P. ficus in artificial diets, followed by feeding on purified virus and subsequent inoculation on $V$. vinifera (three biologic replicates) to determine if transmission could be disrupted. The competitor molecules tested were the lectin wheat germ agglutinin (WGA) with expected affinity to substrates on the cuticle of insect vectors and casein, a molecule commonly used to block nonspecific binding of proteins in immunoassays. Our results show that WGA significantly blocked GLRaV-3-vector transmission to plants (0/45 tested) in comparison to the sucrose controls $(9 / 46)$ (Table $\left.3 ; X^{2}=10.492, p=0.001\right)$. Four of 45 plants were GLRaV-3-positive when blocked with casein, with no significant difference when compared to sucrose controls $(9 / 46)$ $\left(X^{2}=1.963, p=0.161\right)$. As a control, experiments with $P$. ficus fed on sucrose instead of a blocking molecule resulted in 9 of 46 plants infected with GLRaV-3. This provides evidence that the virus binds to $P$. ficus mouthparts and suggests that there is a receptor implicated in virus retention. This assay also provides proof of concept that this approach is valid for testing other compounds capable of blocking transmission. 
Table 3. GLRaV-3-transmission is reduced by a lectin. (a) Results from three biologic replicates of GLRaV-3 blocking transmission tests showing the number of plants infected/plants inoculated. (b) Statistical results from bias-corrected logistic regression testing differences between wheat germ agglutinin (WGA) and casein transmission results from sucrose controls.

\begin{tabular}{ccccc}
\hline \multicolumn{5}{c}{$(\mathbf{a})$} \\
\hline Treatment & $\mathbf{1}$ & $\mathbf{2}$ & $\mathbf{3}$ & Total Positive \\
\hline WGA & $0 / 15$ & $0 / 15$ & $0 / 15$ & $0 / 45$ \\
Casein & $1 / 15$ & $1 / 15$ & $2 / 15$ & $4 / 45$ \\
Sucrose & $4 / 16$ & $3 / 15$ & $2 / 15$ & $9 / 46$ \\
\hline \multicolumn{5}{c}{$(\mathbf{b})$} \\
\hline Treatment & Estimate & SE & $\chi^{2}$ Statistic & $\boldsymbol{P}$ Value \\
\hline Intercept & -1.204 & 0.517 & 6.331 & 0.011 \\
Casein & -0.828 & 0.608 & 1.963 & 0.161 \\
WGA & -3.103 & 1.429 & 10.492 & 0.001 \\
\hline
\end{tabular}

\section{Discussion}

GLRaV-3 is one of the most important viruses of grapevines, but there are significant gaps in our understanding of its transmission biology. GLRaV-3 research has been limited by a labor-intensive and technically challenging host-pathogen system until the recent discovery that GLRaV-3 is capable of infecting an alternative model host, $N$. benthamiana [15]. Building off that study, we determined that GLRaV-3 purifications from both P1/HC-Pro N. benthamiana and V. vinifera could be transmitted through an artificial diet membrane system to healthy plants. The purification protocol used was based on a protocol previously described for LIYV, a related long filamentous virus [16]. As determined in previous work, we eliminated subsequent steps associated with ultra-pure purifications to preserve the integrity of the long flexuous virions as well as maintain virus yields [15].

GLRaV-3-transmission was highest from $V$. vinifera purifications to $V$. vinifera plants compared to transmission to P1/HC-Pro N. benthamiana or from P1/HC-Pro N. benthamiana purifications to $V$. vinifera or P1/HC-Pro N. benthamiana plants. It is possible that transmission could be affected by $P$. ficus host plant preference. Observations of $P$. ficus behavior on $V$. vinifera versus $N$. benthamiana have been previously described and demonstrated that $P$. ficus prefers $V$. vinifera [15]. In these experiments, it was thought that the membrane feeding would eliminate the plant preference component affecting transmission results, but that was not observed given the low transmission rate from $N$. benthamiana purifications; $P$. ficus may reject $N$. benthamiana as a recipient host, or there is some component purified from $N$. benthamiana that deters $P$. ficus feeding on diets. It also may be that $P$. ficus prefers probing plants instead of parafilm, as the transmission rates published in earlier work from $N$. benthamiana or $V$. vinifera plants to both $N$. benthamiana and $V$. vinifera plants were higher [15]. Lastly, virus particle integrity is affected in preparations compared to plant hosts. Future studies should compare GLRaV-3-transmission from purifications with other mealybug species that may feed on N. benthamiana. Furthermore, while this work demonstrates that artificial diets may be used to study mealybug-ampelovirus interactions and that the protocol used for virus purification yields intact particles, methodological improvements would allow for a range of additional hypotheses to be tested.

Because P. ficus transmitted GLRaV-3 from artificial diets through membrane feeding, a unique immunofluorescent localization system previously used to investigate LIYV transmission in whitefly vectors was adapted for this study. This approach proved to have low efficiency in this host-pathogen system compared to the results observed in whiteflies, with 31 out of 645 first-instar $P$. ficus observed with a fluorescent signal (Table 2). A similar pattern was observed in 8 out of 298 P. ficus fed on GLRaV-3-infected source grapevine cuttings instead of viral purifications (Table 2). In order to observe fluorescence, $P$. ficus was required to feed on four different subsequent diets. If the mealybug did not feed on any one of the diets, specific labeling would not be observed, which could explain the low 
numbers of insects with any labeling. We observed fluorescent signals in the anterior foregut region (cibarium) of P. ficus as well as on the retracted stylet tips, regardless of the initial source diet (viral purifications or live plant cuttings). In one insect, a signal was observed in both of these regions at the same time. It is possible that the virus is retained in both sites, but further studies testing other GLRaV-3 variants and mealybug vector species should confirm if transmission of the virus is associated with one or both of the sites. Without associated transmission data, it cannot be concluded whether the retention sites observed are implicated in the transmission of GLRaV-3.

Although it cannot be confirmed which site is associated with transmission from this work, it is encouraging that these results follow trends observed in other virus-vector systems. Both the stylet tips and cibarium regions have been implicated in nonpersistent or semipersistent virus transmission. The retention site of the related noncirculative LIYV has recently been identified in the cibarium of the whitefly vector [6]. Retention sites for other semipersistently transmitted viruses including the leafhopper-transmitted Maize chlorotic dwarf virus, aphid-transmitted Anthriscus yellows virus, and Parsnip yellow fleck virus have also been localized to the tips of stylets or foreguts of insect vectors [21-23]. The stylet tips of aphid vectors were observed to be the retention site for CaMV, another semipersistent virus, as well as Cucumber mosaic virus and other potyviruses [1,24].

In an effort to further characterize the nature of virus-vector interactions, we tested if the transmission of GLRaV-3 could be disrupted by either casein or the lectin wheat germ agglutinin (WGA) [25]. Our results showed that WGA, a lectin with affinity to substrates on the cuticular surface of insect vectors, resulted in significantly lower transmission rates than casein, a molecule used to block nonspecific binding of proteins or the sucrose control. WGA is known to bind to chitin, the long-chain polymer of N-acetylglucosamine, as well as sialic acid, which has been shown to be a receptor for some animal viruses [26]. In Citrus tristeza virus, a member of the Closteroviridae family, virions were shown to bind to the $N$-acetylglucosamine moieties of the cuticular surface of the aphid cibarium [7]. Further studies are needed to determine whether WGA is blocking GLRaV-3 from binding to N-acetylglucosaminated proteins or sialylated proteins in mealybug mouthparts. These results demonstrate that our approach to feed mealybugs blocking molecules and determine transmission rates is valid and that it is feasible to test other molecules for this purpose. Previous work showed that lectins, carbohydrates, antibodies, and peptides affected the transmission rate of Xylella fastidiosa, a noncirculative bacterial pathogen that colonizes the foregut of leafhopper vectors [18,25]. This approach provides only a general idea of the type of vector-pathogen interactions. For vector-borne plant viruses, a specific viral protein is required for virus transmission, and these have been recently described for related viruses in the family Closteroviridae. The minor coat protein (CPm) for the Crinivirus LIYV and both the CPm and heat shock proteins in Citrus tristeza virus, an aphid-transmitted Closterovirus, are viral proteins required for successful retention and transmission by insect vectors [6,7]. Further research investigating the interruption of transmission processes is required to develop novel control strategies as well as develop a basic understanding of transmission mechanisms [27].

In conclusion, our analyses of GLRaV-3-transmission mechanisms suggest that viral retention can be narrowed down to one or two binding sites in P. ficus mouthparts. Although the viral proteins required for binding remain unknown, vector transmission was blocked after binding of WGA, suggesting that the virus interacts with the cuticular surface of the mouthparts. This provides first insights into the transmission biology of this economically important host-pathogen system and demonstrates that mealybug feeding through artificial diet systems works for future studies. Further investigations are needed to elucidate the specific viral proteins required for transmission. The creation of recombinant viral proteins and specific antibodies could help confirm the viral retention site and transmission strategies of this system.

Supplementary Materials: The following are available online at http://www.mdpi.com/1999-4915/12/8/843/s1, Figure S1: Evidence of GLRaV-3 virion retention in the stylet tip of $P$. ficus vectors.

Author Contributions: Conceptualization, C.A.P. and R.P.P.A.; methodology, C.A.P.; validation, C.A.P.; formal analysis, C.A.P.; investigation, C.A.P.; resources, R.P.P.A.; data curation, C.A.P.; writing-original draft preparation, 
C.A.P.; writing-review and editing, C.A.P. and R.P.P.A.; visualization, C.A.P.; supervision, R.P.P.A.; project administration, R.P.P.A.; funding acquisition, R.P.P.A. All authors have read and agreed to the published version of the manuscript.

Funding: C.A. Prator was supported by a National Science Foundation Graduate Research Fellowship.

Acknowledgments: We thank Marilyne Uzest for editing of manuscript and helpful discussions. We thank Bryce Falk for providing seeds of transgenic N. benthamiana plants expressing the turnip mosaic virus P1/HC-Pro sequence and providing helpful guidance during this work. We thank the CNR Biologic Imaging Facility at the University of California, Berkeley for guidance and use of the facility. We are grateful to Foundation Plant Services at the University of California, Davis, for donating known infected virus source material and known virus-free propagation material. This research was supported by the University of California Agricultural Experiment Station.

Conflicts of Interest: The authors declare no conflicts of interest. The funders had no role in the design of the study; in the collection, analyses or interpretation of data; in the writing of the manuscript or in the decision to publish the results.

\section{References}

1. Ng, J.C.; Falk, B.W. Virus-vector interactions mediating nonpersistent and semipersistent transmission of plant viruses. Annu. Rev. Phytopathol. 2006, 44, 183-212. [CrossRef] [PubMed]

2. Whitfield, A.E.; Falk, B.W.; Rotenberg, D. Insect vector-mediated transmission of plant viruses. Virology 2015, 479, 278-289. [CrossRef] [PubMed]

3. Uzest, M.; Gargani, D.; Drucker, M.; Hébrard, E.; Garzo, E.; Candresse, T.; Fereres, A.; Blanc, S. A protein key to plant virus transmission at the tip of the insect vector stylet. Proc. Natl. Acad. Sci. USA 2007, 104, 17959-17964. [CrossRef] [PubMed]

4. Blanc, S.; Drucker, M.; Uzest, M. Localizing viruses in their insect vectors. Annu. Rev. Phytopathol. 2014, 52, 403-425. [CrossRef] [PubMed]

5. Webster, C.G.; Pichon, E.; van Munster, M.; Monsion, B.; Deshoux, M.; Gargani, D.; Calevro, F.; Jimenez, J.; Moreno, A.; Krenz, B.; et al. Identification of plant virus receptor candidates in the stylets of their aphid vectors. J. Virol. 2018, 92, e00432-e18. [CrossRef]

6. Chen, A.Y.S.; Walker, G.P.; Carter, D.; Ng, J.C.K. A virus capsid component mediates virion retention and transmission by its insect vector. Proc. Natl. Acad. Sci. USA 2011, 108, 16777-16782. [CrossRef]

7. Killiny, N.; Harper, S.; Alfaress, S.; El Mohtar, C.; Dawson, W. Minor coat and heat shock proteins are involved in the binding of citrus tristeza virus to the foregut of its aphid vector, Toxoptera citricida. Appl. Environ. Microbiol. 2016, 82, 6294-6302. [CrossRef]

8. Maree, H.J.; Almeida, R.P.; Bester, R.; Chooi, K.M.; Cohen, D.; Dolja, V.V.; Fuchs, M.F.; Golino, D.A.; Jooste, A.E.; Martelli, G.P. Grapevine leafroll-associated virus 3. Front. Microbiol. 2013, 4, 82. [CrossRef]

9. Tsai, C.W.; Chau, J.; Fernandez, L.; Bosco, D.; Daane, K.M.; Almeida, R.P.P. Transmission of Grapevine leafroll-associated virus 3 by the Vine Mealybug (Planococcus ficus). Phytopathology 2008, 98, 1093-1098. [CrossRef]

10. Daane, K.; Bentley, W.; Walton, V.; Malakar-Kuenen, R.; Millar, J.; Ingels, C.; Weber, E.; Gispert, C. New controls investigated for vine mealybug. Calif. Agric. 2006, 60, 31-38. [CrossRef]

11. Herrbach, E.; Alliaume, A.; Prator, C.; Daane, K.; Cooper, M.; Almeida, R. Vector transmission of grapevine leafroll-associated viruses. In Grapevine Viruses: Molecular Biology, Diagnostics and Management; Springer: Berlin/Heidelberg, Germany, 2017; pp. 483-503.

12. Heriot, A. The crumena of the Coccidae and the Adelges. J. Entomol. Soc. BC 1936, 33, 22-24.

13. Uzest, M.; Gargani, D.; Dombrovsky, A.; Cazevieille, C.; Cot, D.; Blanc, S. The "acrostyle": A newly described anatomical structure in aphid stylets. Arthropod Struct. Dev. 2010, 39, 221-229. [CrossRef] [PubMed]

14. Cid, M.; Fereres, A. Characterization of the probing and feeding behavior of Planococcus citri (Hemiptera: Pseudococcidae) on grapevine. Ann. Entomol. Soc. Am. 2010, 103, 404-417. [CrossRef]

15. Prator, C.A.; Kashiwagi, C.M.; Voncina, D.; Almeida, R.P.P. Infection and colonization of Nicotiana benthamiana by Grapevine leafroll-associated virus 3. Virology 2017, 510, 60-66. [CrossRef]

16. Klaassen, V.; Boeshore, M.; Dolja, V.V.; Falk, B.W. Partial characterization of the lettuce infectious yellows virus genomic RNAs, identification of the coat protein gene and comparison of its amino acid sequence with those of other filamentous RNA plant viruses. J. Gen. Virol. 1994, 75, 1525-1533. [CrossRef] 
17. Sharma, A.M.; Wang, J.; Duffy, S.; Zhang, S.; Wong, M.K.; Rashed, A.; Cooper, M.L.; Daane, K.M.; Almeida, R.P.P. Occurrence of grapevine leafroll-associated virus complex in Napa Valley. PLoS ONE 2011, 6, e26227. [CrossRef]

18. Killiny, N.; Rashed, A.; Almeida, R.P.P. Disrupting the transmission of a vector-borne plant pathogen. Appl. Environ. Microbiol. 2012, 78, 638-643. [CrossRef]

19. Heinze, G.; Schemper, M. A solution to the problem of separation in logistic regression. Stat. Med. 2002, 21, 2409-2419. [CrossRef]

20. Heinze, G.; Ploner, M.; Dunkler, D.; Southworth, H. Logistf: Firth's Bias Reduced Logistic Regression (R Package Version 1.21). 2013. Available online: http://finzi.psych.upenn.edu/library/logistf/html/logistfpackage.html (accessed on 6 May 2020).

21. Childress, S.A.; Harris, K.F. Localization of virus-like particles in the foreguts of viruliferous Graminella nigrifrons leafhoppers carrying the semi-persistent maize chlorotic dwarf virus. J. Gen. Virol. 1989, 70, 247-251. [CrossRef]

22. Murant, A.; Roberts, I.; Elnagar, S. Association of virus-like particles with the foregut of the aphid Cavariella aegopodii transmitting the semi-persistent viruses anthriscus yellows and parsnip yellow fleck. J. Gen. Virol. 1976, 31, 47-57. [CrossRef]

23. Ammar, E.; Nault, L. Maize chlorotic dwarf viruslike particles associated with the foregut in vector and nonvector leafhopper species. Phytopathology 1991, 81, 444-448. [CrossRef]

24. Brault, V.; Uzest, M.; Monsion, B.; Jacquot, E.; Blanc, S. Aphids as transport devices for plant viruses. C. R. Biol. 2010, 333, 524-538. [CrossRef] [PubMed]

25. Labroussaa, F.; Zeilinger, A.R.; Almeida, R.P.P. Blocking the transmission of a noncirculative vector-borne plant pathogenic bacterium. Mol. Plant Microbe Interact. 2016, 29, 535-544. [CrossRef] [PubMed]

26. Matrosovich, M.; Herrler, G.; Klenk, H.D. Sialic acid receptors of viruses. Top. Curr. Chem. 2015, 367, 1-28. [PubMed]

27. Whitfield, A.E.; Rotenberg, D. Disruption of insect transmission of plant viruses. Curr. Opin. Insect Sci. 2015, 8, 79-87. [CrossRef]

(C) 2020 by the authors. Licensee MDPI, Basel, Switzerland. This article is an open access article distributed under the terms and conditions of the Creative Commons Attribution (CC BY) license (http://creativecommons.org/licenses/by/4.0/). 